\title{
Triggers of tree mortality under drought
}

Brendan Choat ${ }^{1 *}$, Timothy J. Brodribb², Craig R. Brodersen ${ }^{3}$, Remko A. Duursma ${ }^{1}$, Rosana López ${ }^{1,4}$ \& Belinda E. Medlyn ${ }^{1}$

Severe droughts have caused widespread tree mortality across many forest biomes with profound effects on the function of ecosystems and carbon balance. Climate change is expected to intensify regional-scale droughts, focusing attention on the physiological basis of drought-induced tree mortality. Recent work has shown that catastrophic failure of the plant hydraulic system is a principal mechanism involved in extensive crown death and tree mortality during drought, but the multi-dimensional response of trees to desiccation is complex. Here we focus on the current understanding of tree hydraulic performance under drought, the identification of physiological thresholds that precipitate mortality and the mechanisms of recovery after drought. Building on this, we discuss the potential application of hydraulic thresholds to process-based models that predict mortality.

$\mathrm{F}$ orests account for approximately $45 \%$ of global terrestrial carbon stocks and have a key role in hydrological and nutrient cycles ${ }^{1,2}$. They also provide a wide array of ecosystem services and are vital for maintenance of biodiversity. While forests continue to face pressure from expanding human populations, which drive changes in land use and deforestation, the threat posed by climate change is less easily quantified. Evidence from a range of sources suggests that rising atmospheric $\mathrm{CO}_{2}$ concentrations have benefited forests, with $\mathrm{CO}_{2}$ fertilization enabling an increased leaf area index ${ }^{3}$, enhanced water-use efficiency ${ }^{4}$ and greater uptake of carbon globally ${ }^{5}$. However, extreme climate events, such as heat waves, droughts, fires and storms, have the potential to offset these benefits, causing widespread tree mortality and a net loss of $\mathrm{CO}_{2}$ into the atmosphere. Although forests are vulnerable to a wide range of extreme climate events, drought and associated disturbances have the greatest effect globally ${ }^{6}$. Recent projections ${ }^{7}$ indicate that land surface warming may lead to longer and more intense droughts, which has focused concern on this area of research and the need for accurate predictions of the effects of drought on forest ecosystems. In this Review, we examine the physiological response of trees to drought, focusing on new insights provided by rapid advances in our understanding of the hydraulic function of plants.

Land plants require an efficient long-distance transport pathway to lift water from the soil to the leaves at a rate that satisfies transpiration $^{8}$. In trees, the xylem tissue (wood) supplies water for all aspects of plant function, including photosynthesis, growth and reproduction. Damage to this hydraulic supply network as a consequence of severe water stress has been identified as a key mechanism that is involved in tree mortality during drought ${ }^{9-11}$. Recent experimental work has quantitatively linked hydraulic failure thresholds to plant mortality ${ }^{12,13}$, and field studies have demonstrated that hydraulic failure is a primary pathway for extensive canopy death or plant mortality during natural drought events ${ }^{14-17}$.

A number of other co-contributing factors may also have a role in the death of trees during natural droughts ${ }^{18}$. In the absence of catastrophic hydraulic failure, partial disruption of water transport and the regulation of water loss from plants during drought may lead to an increased likelihood of mortality through the depletion of carbohydrate reserves used in respiration and increased vulnerability to pests and pathogens ${ }^{11}$. Therefore, even in cases of co-morbidity, plant hydraulic traits occupy a central role in determining survival during drought and the effects of drought on carbon dynamics.
Here, we cover recent progress in our understanding of plant hydraulic response to drought and the physiological mechanisms that govern recovery of hydraulic function after drought. Although recent advances have crystallized our understanding of plant hydraulic function and the consequences of vascular impairment caused by drought stress, many challenges remain. We evaluate recent attempts to integrate the hydraulic traits of plants into process-based models of tree mortality with an emphasis on major knowledge gaps.

\section{Drought and forest mortality}

The effect of future droughts will almost certainly be worsened by increases in air temperature associated with global warming; when natural droughts occur they will set in more quickly and be of greater intensity ${ }^{7}$. Higher temperatures will usually result in greater evapotranspiration (the sum of evaporation and plant transpiration), thus drying soil and plants more quickly than would be the case at lower temperatures ${ }^{19}$. Droughts of this nature, termed 'global change-type droughts', have had severe effects on exposed ecosystems including mass tree mortality ${ }^{20,21}$.

Globally, drought is the most widespread stress factor that affects forest carbon balance ${ }^{6}$ with the potential to cause pronounced depressions in gross primary productivity at regional and continental scales ${ }^{22,23}$. The most notable effects of drought are manifested in regional-scale forest mortality events, which can kill millions of trees within short timescales. Recent high-profile examples include extreme droughts in Texas and California, which are estimated to have killed 300 million and 102 million trees, respectively ${ }^{24-26}$. Mass tree mortality due to drought is not restricted to arid regions, having been documented across many forest biomes including cool temperate and tropical forests ${ }^{14-16,27,28}$. In tropical northern Australia, the sudden die-off of more than 7,000 ha of mangrove forest in 2015 was attributed to drought and extreme temperatures ${ }^{28}$. Although such concentrated mortality events are yet to be observed in many of the world's most productive tropical ecosystems, drought events in tropical rainforests (for example, the 2005 Amazon drought) have resulted in marked increases in stem mortality and loss of aboveground biomass ${ }^{29}$. Mortality is often skewed towards young trees but recent evidence suggests that large, old trees are also vulnerable ${ }^{30,31}$. Loss of large trees is particularly concerning because they have a critical ecological role and have the largest biomass and storage of carbon. 
Against this backdrop, it is essential to improve the accuracy with which we can predict the response of trees to drought to understand the resilience of forests under future climate regimes. At present, mortality is not well-represented in vegetation models, owing mostly to gaps in our understanding of physiological mechanisms and a lack of appropriate thresholds with which to parameterize these models. We therefore turn our attention to how these problems may be resolved.

\section{Drought and hydraulic failure in trees}

As with all vascular plants, trees prevent desiccation injury by using an intricate plumbing system of hollow dead cells (vessels or tracheids) to transport water from the soil to the leaves. Xylem transport relies on an elegant mechanism whereby liquid water is held under tension, enabling trees to lift vast volumes of water to the canopy at little energetic $\operatorname{cost}^{32}$. However, liquid water under tension exists in a metastable state, similar to that of a superheated liquid ${ }^{33}$. In this state, water is prone to cavitation, a sudden phase change from liquid water to gas that creates a bubble (embolism). These gas emboli block water flow through xylem conduits and reduce the delivery of water to the canopy and regenerative tissues (that is, apical and cambial meristems $)^{8}$. Drought leads to higher xylem tensions and an increased probability that emboli will spread throughout the xylem network causing systemic vascular dysfunction ${ }^{12,34}$.

\section{Phases of drought stress and the response of plants}

During drought, reduced precipitation leads to declines in soil moisture, which are often accompanied by higher temperatures and increased evaporative demand from the atmosphere. These factors combine to induce water stress in plants, which is manifested as increased tension in the xylem sap. Water stress is measurable in plants as xylem water potential $\left(\Psi_{\mathrm{x}}\right)$, a variable that is primarily determined by pressure in the xylem fluid and becomes increasingly negative during drought $^{32,35}$. As plants desiccate, the loss of cell turgor causes stomatal pores on the leaf surface to close, markedly slowing plant dehydration and the rate of decrease in $\Psi_{\mathrm{x}}$. Most recent studies indicate that stomata in trees close before reaching the threshold $\Psi_{\mathrm{x}}$ at which significant cavitation is initiated, despite the negative consequences of stomatal closure $^{36-38}$ (Fig. 1). On short time scales, these consequences include a rapid cessation of photosynthetic $\mathrm{CO}_{2}$ assimilation, loss of canopy evaporative cooling through transpiration and greater probability of photodamage $^{39,40}$. Over longer time scales, low photosynthetic rates associated with drought-induced stomatal closure can lead to depletion of non-structural carbohydrate pools, which interferes with translocation of sugars through the phloem ${ }^{11,41,42}$ and the production of chemical defence compounds needed to prevent herbivory and disease ${ }^{18,43}$. The fact that stomatal closure generally occurs before the initiation of cavitation despite these costs suggests that avoidance of xylem cavitation is of paramount importance for the long-term survival of trees.

After stomatal closure, $\Psi_{\mathrm{x}}$ continues to slowly decrease, becoming more negative as water is lost through cuticular conductance, stomatal leakiness ${ }^{44}$ and other tissues such as bark ${ }^{45}$. At the same time, hydraulic conductance may decrease throughout the hydraulic pathway of the plant through a number of biophysical and physiological mechanisms, including reversible collapse of leaf veins ${ }^{46}$, regulation of aquaporins in cell membranes ${ }^{47,48}$ and the formation of cortical lacuna in fine roots ${ }^{49}$. Rates of water loss during this phase are typically in the order of 100-1,000-fold less than when the stomata are fully open ${ }^{44}$ and decreases in $\Psi_{\mathrm{x}}$ are further buffered by the release of internally stored water ${ }^{50}$. If drought persists, $\Psi_{\mathrm{x}}$ will ultimately reach a critical threshold at which emboli begin to propagate through the xylem ${ }^{8,51}$. This process occurs throughout the hydraulic pathway including roots, stems and leaves ${ }^{34,48,49,52,53}$ (Fig. 2). Because emboli greatly reduce water delivery to the canopy, this hydraulic dysfunction can cause patchy branch death and pronounced reductions in canopy leaf area ${ }^{54}$. During intense droughts, emboli spread throughout the water transport network, causing systemic failure of the vascular system ${ }^{55}$. In the face of continuing drought and high evaporative demand, systemic vascular dysfunction may cause rapid mortality of the whole plant through desiccation ${ }^{12,15,16}$ and death of the meristematic tissue in the cambium and apical meristems.

\section{Hydraulic traits of trees and adaptations to drought}

The risk of hydraulic failure is an unavoidable consequence of transporting water under tension, and thus forms a fundamental axis of selection in the evolution of trees ${ }^{56,57}$. Strategies to preserve the integrity of the plant vascular system in trees are diverse, but all revolve around a simple framework defined by two constraints: (1) the physical limits of the vascular system; and (2) the capacity to maintain plant water potential within these functional limits. These two attributes dictate how rapidly plant tissues will dehydrate during a drought and the specific thresholds at which water stress will translate into hydraulic failure and mortality ${ }^{37,58}$.

Although it is possible to characterize a general sequence of events that describe the response of vascular plants to drought, the traits that define this response vary across species and environments ${ }^{59-61}$. Recent studies have illustrated the enormous variation in vulnerability to xylem cavitation across tree species, with changes in xylem vulnerability correlated to mean annual precipitation and aridity of their growth environment ${ }^{60}$. Species are typically compared by the $\Psi_{\mathrm{x}}$ value at which a $50 \%$ loss of hydraulic conductance occurs $\left(\Psi_{50}\right)$, although other reference points may have more physiological importance, for example, $\Psi_{88}$ (Fig. 1). Differences in vulnerability are driven by the anatomical features of the xylem, including conduit dimensions, network organization and the porosity of primary cell walls (pit membranes) that limit the spread of gas between conduits ${ }^{62,63}$. These features control the critical $\Psi_{\mathrm{x}}$ at which gas will penetrate pit membranes, causing cavitation in adjacent conduits and the spread of embolism through the xylem ${ }^{8}$. However, vulnerability to cavitation does not determine drought tolerance in itself. The probability of reaching the critical threshold and the length of time it takes for this to occur are determined by the interaction of a number of associated physiological and morphological traits (Fig. 3).

The multi-dimensional nature of such trait interactions has enabled vascular plants to inhabit nearly every terrestrial habitat on Earth and enabled a huge number of possible morphological and physiological solutions to tolerating drought. For instance, variation in the vulnerability of plants is often high within communities, particularly in drier habitats, indicating that vulnerability and aridity are decoupled in some cases $^{64}$. This decoupling results from water-stress avoidance strategies that are used by some species, such as deep root systems or drought deciduousness, that allow them to maintain a higher $\Psi_{\mathrm{x}}$ during drier periods. Although this complexity makes the development of models challenging, a suite of well-studied traits that are mechanistically linked to drought tolerance have now emerged (Supplementary Table 1) and represents a promising direction for future research. Recent analyses have suggested that these traits often vary in a coordinated fashion that allows the benefits of photosynthetic carbon gain to be balanced against the risks of a decrease in $\Psi_{\mathrm{x}}$ and the occurrence of hydraulic failure ${ }^{59,65}$. Thus, much of the complexity of trait interactions may collapse onto a single axis that defines a spectrum of drought tolerance strategies $^{66}$.

Ultimately, we are interested in predicting when a plant will die as a result of drought stress. Vulnerability to cavitation has emerged as a key physiological trait that is associated with mortality, and hydraulic failure represents a critical point in the drought response pathway. Species-specific tree hydraulic limitations provide a powerful mechanistic explanation for the observation that drought mortality is occurring across forest biomes, independent of the mean rainfall at any site. A recent data synthesis demonstrated that the majority of plant species converge to narrow hydraulic safety margins, that is, the buffer between minimum water potential experienced by the plant $\left(\Psi_{\min }\right)$ and the threshold $\Psi_{\mathrm{x}}$ for rapid loss of vascular function caused by cavitation ${ }^{60}$. Because $\Psi_{\min }$ integrates many important aspects of plant structure (for example, rooting depth) and physiology (for example, stomatal 


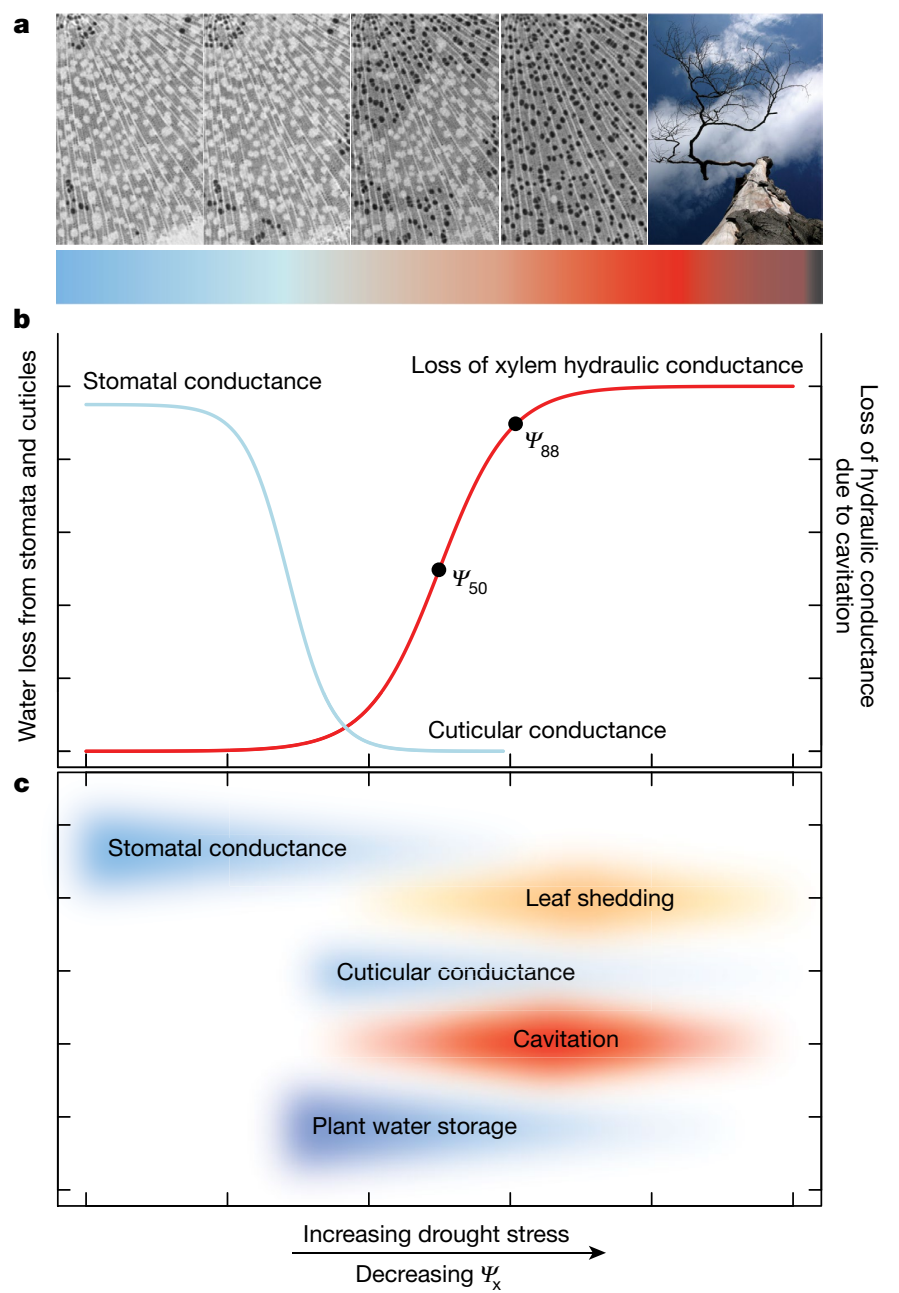

Fig. 1 | Phases of drought response in plants. a, Time series of transverse slices through the xylem tissue obtained by X-ray microtomograpy show the spread of gas emboli through the xylem with increasing drought stress (left to right). In each slice, water-filled vessels are seen as bright circles whereas vessels that contain gas emboli are black. During severe drought, almost all vessels become gas-filled, which leads to whole-plant mortality (right). b, During the first phase, stomata close to limit water loss and delay the decrease in xylem water potential (blue line). After stomata close, water continues to be lost at a much lower rate via cuticular conductance.

behaviour) in relation to the environment, the narrow safety margins that are found across forest types offer an important insight into plant ecology, one that suggests that the hydraulic strategies of plants are finely tuned to their environment, allowing for maximum carbon gain but exposing plants to the risk of hydraulic failure during drought. It also suggests a generally 'risky' strategy in which plants have limited physiological potential to respond to rapid changes in the environment. This exacerbates the threat posed by increased occurrences of extreme drought under climate change. Indeed, drought mortality events across forests from a broad geographical and climatic range have been linked quantitatively to hydraulic traits and xylem cavitation ${ }^{67}$. Examples come from tropical rainforest ${ }^{68}$, temperate forests ${ }^{14,16}$, chaparral $^{15,17}$ and desert woodlands ${ }^{11}$. Many of these studies show differential species mortality within each forest type, allowing us insights into the potential winners and losers under future drought regimes.

\section{Plasticity and genetic variation in hydraulic traits}

Although much is known about the variability in hydraulic traits among plant species, far fewer data are available to quantify within-species variation. The capacity of trees to alter phenotype (that is, phenotypic plasticity) and the amount of genetic diversity within a population are key variables for the ability of species to cope with rapid climate change.
At a critical threshold, cavitation increases rapidly and gas emboli spread throughout the xylem (red line). Increasing levels of embolism are shown as the proportional loss of xylem hydraulic conductance. 'Vulnerability curve' analysis translates the physics of cavitation to a quantification of species susceptibility to cavitation during exposure to water stress. These mortality thresholds have been found to correspond to between $50 \%\left(\Psi_{50}\right)$ and $88 \%\left(\Psi_{88}\right)$ loss of hydraulic function in conifers and angiosperms, respectively. c, A general scheme for the magnitude and timing of response processes with increasing drought stress.

It is unlikely that trees will be capable of adapting to sudden increases in the aridity of their environment through evolutionary mechanisms, because of their long generation cycle and inability to migrate away from stress. On the other hand, adaptive plasticity of hydraulic traits may enable the acclimatization of entire populations within the necessary timescales. Quantifying the extent of plasticity in hydraulic traits is therefore an essential component for the prediction of the tolerance ranges and resilience to drought of different species. However, comprehensive datasets that examine the genetic variation and phenotypic plasticity of vulnerability to cavitation have only recently become available and are limited to a few species. A study of 513 genotypes of the widespread pine species Pinus pinaster showed low genetic variation of $\Psi_{50}$ between climatically contrasting populations and very limited phenotypic plasticity ${ }^{69}$. These results suggest that $\Psi_{50}$ may be a canalized trait in pines, with little capacity to enable short-term acclimatization and adaptive plasticity. Angiosperm species have a higher potential for phenotypic plasticity and adaptive variation between populations ${ }^{70}$, although the observed shifts in vulnerability are often small in magnitude relative to changes in $\Psi_{\mathrm{x}}$ that are expected to occur during severe drought.

Long-term manipulative experiments suggest that structural acclimatization, that is, changes in the allocation pattern between 

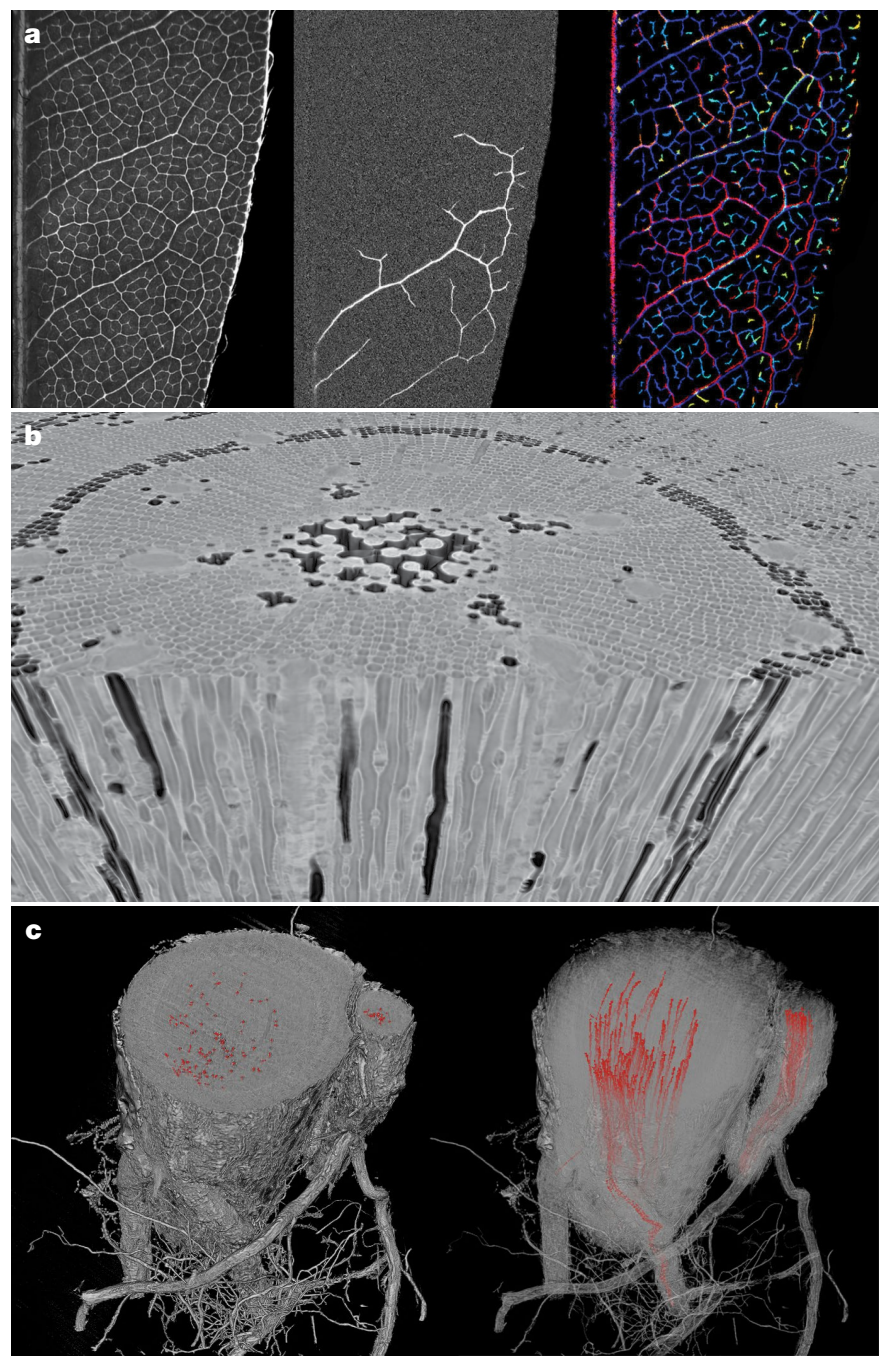

Fig. 2 | Non-invasive imaging techniques have provided new insights into embolism formation and spread in the xylem. a, Mapping the spread of embolism in leaf vein networks during dehydration with transmitted light. Left, transmitted light images highlighting the vein network. Middle, image subtraction reveals embolism propagating from the midrib into the secondary and tertiary venation. Right, a colour map of all cavitation events recorded during desiccation. $\mathbf{b}$, Three-dimensional rendering from a X-ray micro-computed tomograph of a pine stem. Embolized tracheids can be seen clearly as a black void space surrounded by water-filled (grey) tracheids. c, Part of a root system rendered from a micro-computed tomograph showing embolized xylem vessels (red) in the main root axis and lateral roots during dehydration. Right, the root tissue has been made transparent to illustrate the pathway of embolized vessels. Images in a were reproduced with permission from Brodribb et al. ${ }^{52}$.

water-absorbing, -conducting and -transpiring tissues, is almost certainly the dominant process by which plants adjust their hydraulic systems in response to drought ${ }^{71}$. Reductions in the leaf to sapwood area ratio and shoot to root ratio result in a greater capacity to supply water to the leaves and limit the drop in $\Psi_{\text {min }}$, consistent with homeostasis of water transport, however these changes come at the cost of reductions in productivity ${ }^{72}$. Reductions in the leaf to sapwood area ratio result in the maintenance of a higher $\Psi_{\mathrm{x}}$ and a greater capacity to supply water to the leaves ${ }^{73}$. These results are consistent with studies of intraspecific variation in hydraulic architecture across aridity gradients, which show changes in morphology and allocation patterns; however, little evidence of adaptive variation in vulnerability to cavitation has been found in these studies, even in species with a wide climate envelope ${ }^{74,75}$. Further studies are clearly required to determine whether these patterns can be generalized, particularly in angiosperms, and what role the plasticity of hydraulic traits may have in the capacity of plants to survive increased aridity.

\section{Predicting mortality from hydraulic thresholds}

Predictions of drought-induced forest mortality require a detailed understanding of the physiological underpinnings of tree death. Accordingly, this topic has received much attention in recent years and substantial progress has been made in our understanding of the mechanisms of tree mortality ${ }^{11,12}$. It is clear that drought-associated forest mortality is complex and a number of interdependent mechanisms have important roles in this process. These mechanisms include failure of water transport in the xylem, depletion of carbohydrate reserves over prolonged drought ${ }^{41,42}$ and increased vulnerability to pests and pathogens ${ }^{18,76}$. All mechanisms of drought-associated mortality revolve around the effects of stomatal closure and increasing xylem tension during water shortage. Hydraulic failure is the most fully elaborated mechanism and currently holds the most promise for predictive models. It is a relatively well-understood biophysical process that is amenable to modelling ${ }^{77}$, with failure thresholds that can be readily established for a given species or population ${ }^{69,70}$. Accuracy and confidence in the vulnerability thresholds that are chosen to represent different species in predictive models are absolutely critical. Recent technical and theoretical advances in the science of plant hydraulics have provided new certainty in the quantitative nature of hydraulic failure $^{34,55,78}$. We thus focus on hydraulic traits as a means to understand and predict patterns of tree mortality in response to drought while emphasizing that other thresholds can be incorporated as our understanding of them improves. Indeed, incorporation of hydraulics thresholds, such as turgor loss and stomatal closure, should assist greatly in predicting carbon dynamics under drought.

\section{Measuring hydraulic thresholds to mortality}

As noted above, tree species exhibit a large range in xylem vulnerability ${ }^{60,61}$. Clear links between xylem cavitation and tree death have been established in pot studies ${ }^{10,12,13}$ and natural systems ${ }^{15,79,80}$, suggesting that xylem vulnerability should undergo strong selection in species exposed to episodic water stress. Evidence of selection, or ecological sorting, can be seen in the distribution of species with regard to strong correlations between aridity and xylem vulnerability ${ }^{10,56,64}$. The exciting implication of this work is that the vulnerability of xylem tissue to cavitation provides a measurable index of the capacity of a species to tolerate water stress during drought ${ }^{77}$.

Our ability to predict the level of water stress at which a plant will die based on functional traits has advanced considerably in recent years. The concept of a 'lethal water potential' for a given plant species or population has existed for some time, but only recently has hydraulic vulnerability been quantitatively linked to mortality ${ }^{12}$. In conifers, the $\Psi_{50}$ of the stem xylem is strongly related to their 'minimum recoverable water potential', essentially a physiological point of no return ${ }^{12,81}$. By contrast, the lethal water potential of angiosperm species is correlated with more complete hydraulic dysfunction, representing $80-100 \%$ loss of xylem hydraulic conductance $\left(\Psi_{88}\right)^{10,13}$. The disparity in mortality thresholds between conifers and angiosperms may be related to the fundamental difference in xylem structure between these two groups and goes some way to explaining the generally larger hydraulic safety margins and more conservative stomatal behaviour exhibited by conifer species $^{60,82}$. Other hydraulic thresholds for mortality have been proposed, including a sustained loss of hydraulic conductance greater than $60 \%{ }^{80,83}$. We note that these studies were based on modelled thresholds of whole-plant conductance in two conifer species and compare well to the $\Psi_{50}$ threshold that has been established for conifers experimentally. A recent data synthesis found that all studies reported a $60 \%$ or greater loss in hydraulic conductance at death with a mean loss of $83 \%{ }^{9}$. Therefore, although there are some discrepancies between proposed thresholds, it is clear that high levels of xylem embolism are linked with mortality. Modern techniques for the measurement of water potential and non-invasive visualization of embolism are providing more 


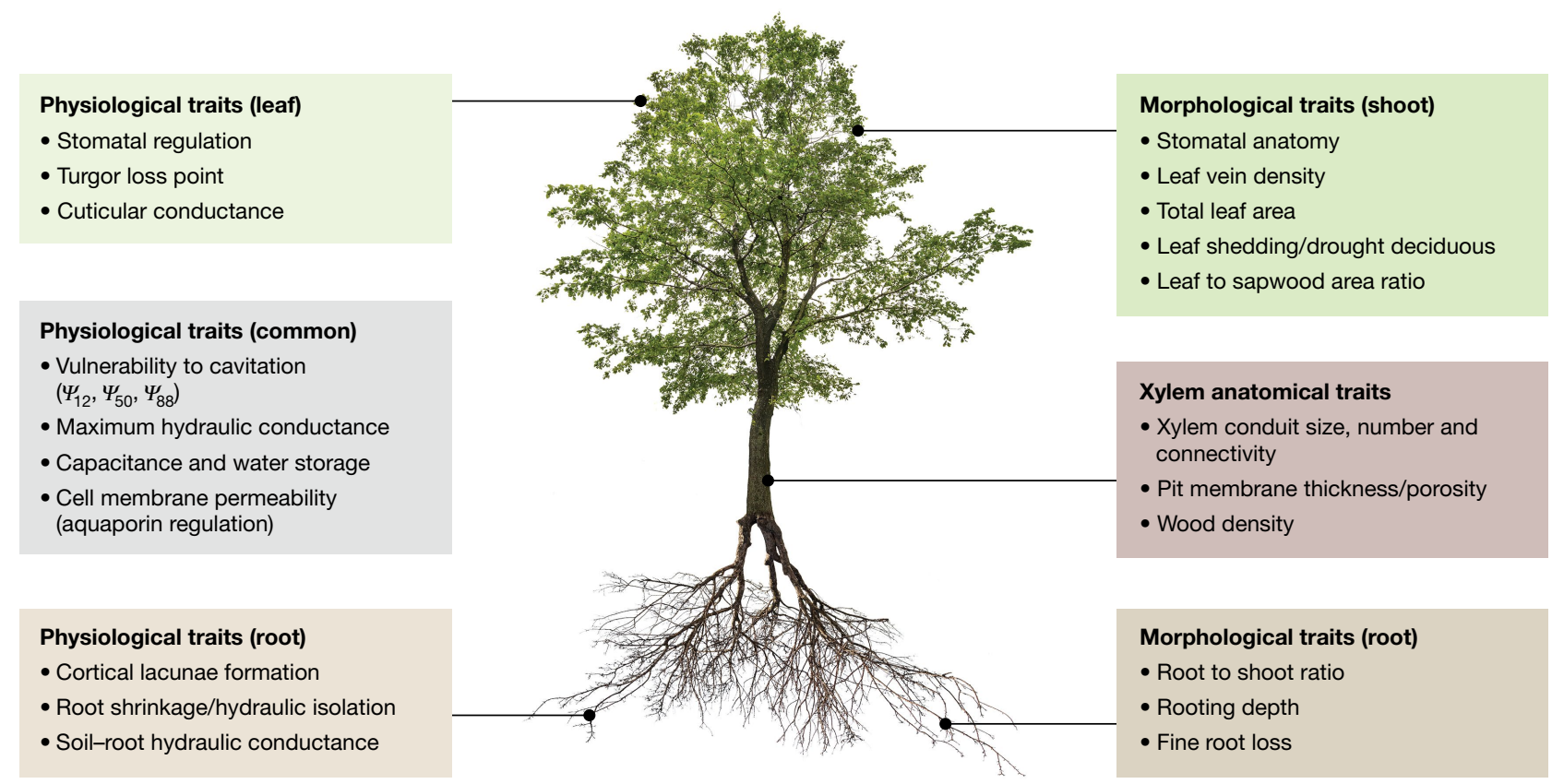

Fig. 3 Tree hydraulic traits associated with drought-induced mortality. Trees use a variety of interdependent and coordinated morphological, anatomical and physiological traits to mitigate water loss and the development of increasingly negative xylem sap pressures during drought. This includes tissue-specific traits that function in the unique microenvironment of roots, stems and leaves, as well as traits that are common among most tissue types in trees. Many structure-function

accurate measures of hydraulic failure thresholds ${ }^{34,55}$, which can then be used to parameterize models of tree mortality.

\section{Trait-based models of tree mortality}

Although the vulnerability of xylem to cavitation defines a threshold in water stress beyond which tree mortality will occur, the key issue for predicting mortality is the ability to translate meteorological data (for example, precipitation or evaporative demand) into plant water content or xylem tension ${ }^{58}$. This calculation presents a number of challenges: it requires knowledge of the volume of water that is available to a plant in the soil and internal reservoirs, as well as the rate of water loss through transpiration. Calculating the amount of water in the soil that is available to the plant is made difficult by a paucity of data relating to rooting depth of trees and the architecture of the roots. Simulating the rate of water loss is complicated by the active regulation of transpiration by stomata, differences in cuticular transpiration after stomatal closure and the degree of leaf shedding during drought. To date, most attempts to model or predict mortality use empirical relationships between observed mortality and climate extremes ${ }^{84,85}$. Such empirical relationships, although they provide insights into the current drivers of mortality, may not function well in the future if plant sensitivities change over time or if novel climate conditions occur. For example, rising $\mathrm{CO}_{2}$ concentrations may alleviate drought stress, whereas rising temperatures may exacerbate it ${ }^{86}$. Empirical relationships may also fail in regions where long-term shifts towards a novel, drier climate are occurring. Process-based models are thus highly desirable ${ }^{87}$.

Recent progress in the understanding of the hydraulic mechanisms that lead to mortality, and quantification of the key plant traits that are involved, has led to the incorporation of plant hydraulics in a range of process-based vegetation models ${ }^{83,88-90}$. The key elements of such models are a description of the soil-to-leaf hydraulic pathway, incorporating soil, root, xylem and stomatal conductances, whole-plant capacitance and the vulnerability of the xylem to cavitation. Important plant traits that are required for parameterization include the response of stomata to decreasing water potential, the point at which leaf turgor is lost, relationships exist between traits, for example, variation in xylem anatomical traits (pit membrane porosity, conduit size and connectivity) determine species and population-level vulnerability to cavitation. Note that this figure does not represent an exhaustive list of hydraulic traits relevant to the response of trees to drought and drought-induced mortality.

saturated xylem hydraulic conductance and water potential thresholds of vulnerability to cavitation. Recent compilation efforts have made data for these traits available for a wide range of species ${ }^{60,91}$ and enabled hydraulic traits to be related to other aspects of the plant economic spectrum $^{88,89}$. Incorporating trait variation in drought sensitivity among species or genotypes, and relating this variation to plant wateruse strategies and other plant properties, promises to be an effective way forwards.

Nonetheless, critical gaps remain in our ability to describe the hydraulic pathway and its eventual failure. Here we draw attention to several gaps that hinder model development and parameterization and that have received comparatively little attention: (1) the dynamics of canopy leaf area during drought; (2) the dependence of plant water status on soil water potential; and (3) the process of plant desiccation in very dry soil, when root water uptake is no longer possible.

First, leaf shedding occurs in many ecosystems during drought ${ }^{92}$, and can mitigate water stress to the remaining foliage ${ }^{93}$, slowing the rate of desiccation (the 'hydraulic fuse' hypothesis ${ }^{53}$ ). However, drought deciduousness is, as yet, poorly captured in models ${ }^{94}$. Recently, it has been demonstrated that representing vegetation as a set of competing plant types with varying degrees of drought deciduousness leads to a marked improvement in modelled leaf area dynamics in Central America; this hydraulics-based approach holds considerable promise for model improvement ${ }^{89}$.

Second, a key component of the hydraulic pathway is the relationship between plant water status (represented by pre-dawn plant water potential, $\Psi_{\text {pd }}$ ) and soil water availability (represented by soil water potential, $\left.\Psi_{\text {soil }}\right)$. Simple models that treat soil water as a single bucket generally fail to capture this relationship; it appears that models need to incorporate vertical gradients in soil moisture potential, the distribution of roots and changing soil-root resistance with soil drying ${ }^{88,95}$. However, it is also commonly observed that co-occurring species can have different $\Psi_{\text {pd }}$ when $\Psi_{\text {soil }}$ is the same ${ }^{96}$, and this difference cannot always be explained by rooting distributions. The $\Psi_{\mathrm{pd}}$ can be lower than $\Psi_{\text {soil }}$ if overnight equilibration is insufficient ${ }^{89}$, or considerable amounts of 
night-time transpiration occur ${ }^{97}$. On the other hand, root shrinkage or cortical deformation in dry soil can create an air gap around roots ${ }^{49,98}$, preventing equilibration and leading to a $\Psi_{\mathrm{pd}}$ that is less negative than the $\Psi_{\text {soil }}$. Foliar water uptake can also lead to shoot rehydration disequilibria with $\Psi_{\text {soil }}$ and these effects can be important for arid environments ${ }^{99}$. There has been little focus to date on the ability of models to replicate measurements of $\Psi_{\mathrm{pd}}$.

Third, it is clear that processes that occur after stomatal closure are important, however these processes have been given less consideration in models ${ }^{58,100}$. Stomata generally close well before the thresholds for pronounced cavitation are reached ${ }^{37,59,101}$. Further increases in cavitation will occur only if models also represent plant water loss when stomata are closed. In very dry soil, the uptake of water by roots is no longer possible and plants have to rely on their internal water storage for survival ${ }^{16,58}$. Plant water storage (an absolute amount of water) is distinct from the capacitance (the slope of water content versus potential). Whereas capacitance is often incorporated into models because it determines the dynamics of the water potential in leaves ${ }^{102}$, plant water storage is not. The depletion rate of the plant water store when stomata are (nearly) closed is governed by the plant leaf area (discussed above), cuticular conductance ${ }^{44}$ and, probably less importantly, water loss through the bark ${ }^{45}$. Comparatively few measurements are available on cuticular conductance and plant water storage $e^{58}$, hindering model parameterization for this final phase towards drought mortality. At this point, very few process-based models that have aimed to simulate drought mortality incorporate both plant water storage and cuticular conductance. A notable exception is provided by the recently developed SurEau model ${ }^{37}$.

In summary, trait-based models that incorporate our best understanding of hydraulic processes hold promise for predicting plant mortality in response to drought. We have highlighted three processes that deserve further attention, both in terms of model development and compilation of necessary data for parameterization. There are likely to be other problems as well, perhaps even larger ones-it is worth noting that no purely process-based model has yet been successful in predicting tree mortality ${ }^{90}$. Model testing must thus continue before we can defensibly use these models for forecasting. We recommend a close coordination between experimentalists and modellers to improve models and their evidence base.

\section{Recovery of hydraulic capacity}

Although much attention has been devoted to determining the physiological basis of tree mortality during drought, it is equally important to understand the processes of recovery in trees that survive drought. What are the effects of drought on the hydraulic function of plants and how quickly can plants recover to the pre-drought levels of physiological performance? Predicting the resilience and recovery of forests is complicated by the predisposition of trees that enter a drought event, which includes the cumulative effects of previous water deficit, pest outbreaks and forest demographics, as well as potential delays between stress events that influence survival, mortality and recovery processes ${ }^{16,58,103,104}$. Recovery of trees after drought is therefore complex, dynamic and determined by at least (1) the degree of damage to the apical and cambial meristematic tissues; (2) the functional status of the remaining hydraulic pathway; (3) the overall health of trees (that is, the remaining foliage and roots); and (4) the water, non-structural carbohydrates and nutrients that are available during the recovery phase.

Mild drought stress does not typically result in high levels of cavitation, although it may result in the transient and easily reversible loss of hydraulic capacity that is associated with mechanisms such as conduit collapse in leaf veins and aquaporin regulation of cell membrane permeability ${ }^{46-48}$. In cases in which drought stress has caused considerable hydraulic dysfunction without mortality, hydraulic recovery could occur by two mechanisms: new wood formation or by refilling embolized conduits. Regrowth of the xylem appears to be the primary means by which trees recover hydraulic capacity after drought ${ }^{12,81}$. This straightforward process involves the addition of new conduits (vessels or tracheids) to outer regions of the xylem through the activity of the vascular cambium. This replaces the hydraulic conductance that is lost by embolized conduits, which may then become permanently occluded by gums or tyloses ${ }^{105}$. In cases in which drought has caused considerable death of aboveground biomass, recovery may be facilitated by resprouting of stems from epicormic buds or lignotubers ${ }^{106}$. The prevalence of resprouting is highly variable among tropical and temperate forest species and is ultimately dependent on the protection and survival of the meristematic tissue to produce new shoots ${ }^{106,107 .}$

An alternative mechanism for recovery of hydraulic capacity, which would be far more rapid than regrowth, is refilling of embolized xylem conduits. Much research has focused on the potential active mechanisms by which plants could refill embolized xylem conduits after drought ${ }^{108-110}$. Springtime refilling following freeze-thaw cycles that produce embolism over winter is well-documented and apparently dependent on the positive pressure that is generated in the roots or stems of deciduous angiosperms ${ }^{111-113}$. A number of studies have shown rapid refilling of embolized vessels after mild drought in herbaceous species ${ }^{114,115}$ and previous studies have suggested that daily cycles of cavitation and refilling are common in some tree species ${ }^{116,117}$. However, recent work has cast doubt on this phenomenon and convincing evidence for short-term refilling after drought in large trees is generally lacking ${ }^{108}$. It appears unlikely that trees can establish the positive pressure that is required to remove emboli in transpiring tissues many metres above the soil surface, making refilling under sustained tension within the current theoretical framework thermodynamically untenable ${ }^{109}$. Although it is thought that some woody species can remove drought-induced emboli within hours or days after a soil-saturating event in combination with non-transpiring conditions, this has only been documented unambiguously in grapevines, which are well-known for their capacity to produce considerable root pressure ${ }^{118,119}$. Other studies using non-invasive imaging have failed to provide evidence of refilling in woody species after drought ${ }^{51,120,121}$. Thus, we believe it is unlikely that refilling in trees is a common mechanism for rapid recovery of hydraulic capacity after drought, although further experimental studies are required to confirm this.

The rate of hydraulic recovery after exposure to drought is largely is dictated by the extreme of negative water potential that is reached, and the amount of time that is spent at this extreme. Drought recovery after rainfall occurs on very short time scales if high levels of cavitation have not taken place ${ }^{122}$ with the rapid opening of stomata to fix new carbon from the atmosphere as plants re-hydrate. However, in cases in which cavitation thresholds are breached, the recovery of photosynthesis is much slower ${ }^{122}$ and proceeds in coordination with the onset of the restoration of hydraulic condutance from the soil to the canopy $^{12,81}$. Growth of new xylem to replace compromised tissues requires long-distance signalling from the roots and leaves ${ }^{123}$, and xylogenesis is affected by the post-drought environment because of sensitivity to temperature, plant growth regulators, carbohydrate pools and water availability ${ }^{124,125}$. Following drought, trees invest substantial carbon resources into rebalancing the root to shoot ratio ${ }^{126}$, increasing fine root biomass, and exploring deeper regions of the soil profile to recover plant water status ${ }^{127}$. Because meristematic tissue is dependent on adequate water availability and phloem transport to establish the turgor that is necessary for xylem cell expansion ${ }^{128}$, xylem development during drought conditions is often markedly reduced. Thus, functional water transport and signalling pathways must be in place to coordinate these events and initiate recovery.

\section{The way forwards}

Hydraulic physiology is central to our understanding of how trees respond to drought, and the pathways leading to drought-induced mortality. Because the hydraulic system is fundamentally linked to carbon balance through stomatal regulation, a mechanistic understanding of plant hydraulic function should greatly improve modelling of vegetation dynamics under water-limiting conditions. With recent progress in methodology, we now stand at an exciting threshold in the field. 
There is potential for great leaps in our understanding of plant hydraulic function and our ability to quantitatively link these physiological mechanisms to forest ecology. Despite this, many important challenges remain. Below, we outline research priorities and key knowledge gaps that constrain our ability to predict drought-induced mortality and recovery after drought.

In terms of manipulative drought experiments, it is clear that studies incorporating long-term droughts on large trees are essential. Thresholds for hydraulic failure have typically been determined on small plants with intense drought treatments and important differences may exist in large trees exposed to droughts of greater duration. This is particularly applicable to determining the time a tree must spend at or below a particular threshold in order for mortality to occur. Long-term experiments will also provide an improved understanding of how tree water relations and carbon balance interact to cause mortality during prolonged droughts.

Better monitoring of plant water potential in communities under drought is also essential in this context. The importance of $\Psi_{\min }$ as a parameter cannot be understated, since the $\Psi_{\mathrm{x}}$ reached by plants is what largely determines the probability that hydraulic failure occurs. It integrates many aspects of plant structure and physiology, and their interaction with climatic and edaphic variables ${ }^{78}$. Other thresholds, such as the point at which leaf turgor is lost and stomatal closure occurs, can be predicted for a species based on continuous $\Psi_{\mathrm{x}}$ data, although seasonal acclimatization in these parameters needs to be taken into account. Unfortunately, datasets of $\Psi_{\min }$ are typically patchy because of the laborious onsite measurement techniques that are involved. Continuous remote monitoring of $\Psi_{\mathrm{x}}$ is now becoming possible because of the development of a new generation of wireless sensors that can be deployed at remote sites ${ }^{129,130}$. This will enable a much higher resolution of $\Psi_{\text {min }}$, the true maximum level of stress that trees are exposed to during natural droughts, and how long they spend at a given $\Psi_{\mathrm{x}}$.

Improved methodology for the measurement of vulnerability to cavitation is also being developed to enable in situ measurement of hydraulic thresholds $\mathrm{s}^{52,55}$ and more rapid phenotyping of thresholds across species and populations ${ }^{69}$. Non-invasive imaging techniques, such as X-ray micro-computed tomography and magnetic resonance imaging, are providing new insights into plant hydraulic function and response to drought. Although these techniques are often costly or difficult to access, they provide unparalleled spatial and temporal resolution for observations in living, intact plants. Further work in this area will be vital to unravel some persistent mysteries of plant vascular transport including the phenomenon of embolism repair after drought and the degree to which it is active in woody plants. Improvements in techniques are also essential for the quantification of plasticity within species and their capacity to acclimatize or adapt to drier conditions. A recently developed optical technique shows great promise to facilitate cost-effective high-throughput measurements of vulnerability to cavitation in leaves, stems and roots ${ }^{34}$. Methods that use centrifugal force to generate vulnerability curves also enable rapid phenotyping ${ }^{69}$ provided the appropriate methodological precautions are observed ${ }^{131}$.

The use of whole-tree techniques, for example, sap flow, is necessary to provide datasets that interface with databases of tissue-level traits. Measuring sap flow and consolidating existing sap flow datasets worldwide (for example, the Sapfluxnet project) ${ }^{132}$ represent important steps in linking tissue-level hydraulic traits to water fluxes and testing large-scale model predictions of the effect of water stress on plants and ecosystems. At a broader scale, remote-sensing tools will be essential to monitor tree mortality and the dynamics of drought recovery. Although there are issues to be solved with detection of mortality using satellite-based sensors ${ }^{133}$, aircraft-based sensors are delivering better resolution of water stress and tree death at stand and regional scales ${ }^{24}$. Although the goal of attaining accurate model predictions of tree mortality due to drought remains elusive, resolution of the challenges outlined above represents a clear path forward. Success in this area will require direct collaboration between experimentalists and modellers, as the effective parameterization of process-based models depends on the acquisition and sharing of often hard-won data (for example, rooting depth, cuticular conductance and cavitation resistance). Finally, we emphasize that hydraulic failure is not the only pathway to mortality associated with drought but rather the most tractable to address with process-based models at this time. The future integration of other physiological thresholds, as well as interactions with pests and pathogens, is the natural course along which we should proceed.

Received: 19 October 2016; Accepted: 2 May 2018; Published online 27 June 2018.

1. Bonan, G. B. Forests and climate change: forcings, feedbacks, and the climate benefits of forests. Science 320, 1444-1449 (2008).

2. Pan, Y. et al. A large and persistent carbon sink in the world's forests. Science 333, 988-993 (2011).

3. Zhu, Z. et al. Greening of the Earth and its drivers. Nat. Clim. Change 6, 791-795 (2016).

4. Keenan, T. F. et al. Increase in forest water-use efficiency as atmospheric carbon dioxide concentrations rise. Nature 499, 324-327 (2013).

5. Wenzel, S., Cox, P. M., Eyring, V. \& Friedlingstein, P. Projected land photosynthesis constrained by changes in the seasonal cycle of atmospheric $\mathrm{CO}_{2}$. Nature 538, 499-501 (2016).

6. Reichstein, M. et al. Climate extremes and the carbon cycle. Nature $\mathbf{5 0 0}$, 287-295 (2013)

7. Trenberth, K. E. et al. Global warming and changes in drought. Nat. Clim. Change 4, 17-22 (2014).

8. Tyree, M. T. \& Zimmermann, M. H. Xylem Structure and the Ascent of Sap (Springer, New York, 2002).

9. Adams, H. D. et al. A multi-species synthesis of physiological mechanisms in drought-induced tree mortality. Nat. Ecol. Evol. 1, 1285-1291 (2017).

10. Kursar, T. A. et al. Tolerance to low leaf water status of tropical tree seedlings is related to drought performance and distribution. Funct. Ecol. 23, 93-102 (2009).

11. McDowell, N. et al. Mechanisms of plant survival and mortality during drought: why do some plants survive while others succumb to drought? New Phytol.

178, 719-739 (2008)

This study introduces a theoretical framework for understanding physiological mechanisms that underpin drought-induced mortality in trees.

12. Brodribb, T. J. \& Cochard, H. Hydraulic failure defines the recovery and point of death in water-stressed conifers. Plant Physiol. 149, 575-584 (2009). This study quantitatively links hydraulic failure thresholds to whole-plant mortality.

13. Urli, M. et al. Xylem embolism threshold for catastrophic hydraulic failure in angiosperm trees. Tree Physiol. 33, 672-683 (2013).

14. Nardini, A., Battistuzzo, M. \& Savi, T. Shoot desiccation and hydraulic failure in temperate woody angiosperms during an extreme summer drought. New Phytol. 200, 322-329 (2013).

15. Venturas, M. D. et al. Chaparral shrub hydraulic traits, size, and life history types relate to species mortality during California's historic drought of 2014 PLOS ONE 11, e0159145 (2016).

16. Anderegg, W. R. et al. The roles of hydraulic and carbon stress in a widespread climate-induced forest die-off. Proc. Natl Acad. Sci. USA 109, 233-237 (2012).

17. Davis, S. D. et al. Shoot dieback during prolonged drought in Ceanothus (Rhamnaceae) chaparral of California: a possible case of hydraulic failure. Am. J. Bot. 89, 820-828 (2002).

18. McDowell, N. G. et al. The interdependence of mechanisms underlying climate-driven vegetation mortality. Trends Ecol. Evol. 26, 523-532 (2011).

19. Duan, $\mathrm{H}$. et al. Elevated $\left[\mathrm{CO}_{2}\right]$ does not ameliorate the negative effects of elevated temperature on drought-induced mortality in Eucalyptus radiata seedlings. Plant Cell Environ. 37, 1598-1613 (2014).

20. Allen, C. D., Breshears, D. D. \& McDowell, N. G. On underestimation of global vulnerability to tree mortality and forest die-off from hotter drought in the Anthropocene. Ecosphere 6, 129 (2015).

21. Carnicer, J. et al. Widespread crown condition decline, food web disruption, and amplified tree mortality with increased climate change-type drought. Proc. Natl Acad. Sci. USA 108, 1474-1478 (2011).

22. Ciais, P. et al. Europe-wide reduction in primary productivity caused by the heat and drought in 2003. Nature 437, 529-533 (2005).

23. Lewis, S. L., Brando, P. M., Phillips, O. L., van der Heijden, G. M. F. \& Nepstad, D. The 2010 Amazon drought. Science 331, 554 (2011).

24. Asner, G. P. et al. Progressive forest canopy water loss during the 2012-2015 California drought. Proc. Natl Acad. Sci. USA 113, E249-E255 (2016).

25. Moore, G. W. et al. Tree mortality from an exceptional drought spanning mesic to semiarid ecoregions. Ecol. Appl. 26, 602-611 (2016).

26. USDA Forest Service Pacific Southwest Region. Aerial Detection Surveys Report: Summary for May 15-19 Report No. fseprd506698 (USDA Forest Service, 2016).

27. Allen, C. D. et al. A global overview of drought and heat-induced tree mortality reveals emerging climate change risks for forests. For. Ecol. Manage. 259, 660-684 (2010).

This study summarizes forest mortality events associated with drought and heat over the last four decades.

28. Duke, N. C. et al. Large-scale dieback of mangroves in Australia's Gulf of Carpentaria: a severe ecosystem response, coincidental with an unusually extreme weather event. Mar. Freshw. Res. 68, 1816-1829 (2017). 
29. Phillips, O. L. et al. Drought sensitivity of the Amazon rainforest. Science $\mathbf{3 2 3}$ 1344-1347 (2009).

30. da Costa, A. C. L. et al. Effect of $7 \mathrm{yr}$ of experimental drought on vegetation dynamics and biomass storage of an eastern Amazonian rainforest. New Phytol. 187, 579-591 (2010).

31. Lindenmayer, D. B. \& Laurance, W. F. The ecology, distribution, conservation and management of large old trees. Biol. Rev. Camb. Philos. Soc. 92 1434-1458 (2016).

32. Slatyer, R. O. Plant-Water relationships (Academic, New York, 1967).

33. Debenedetti, P. G. Metastable Liquids: Concepts and Principles (Princeton Univ. Press, Princeton, 1996).

34. Rodriguez-Dominguez, C. M., Carins Murphy, M. R., Lucani, C. \& Brodribb, T. J. Mapping xylem failure in disparate organs of whole plants reveals extreme resistance in olive roots. New Phytol. 218, 1025-1035 (2018).

35. Scholander, P. F., Hammel, H. T., Bradstreet, E. D. \& Hemmingsen, E. A. Sap pressure in vascular plants. Science 148, 339-346 (1965)

36. Hochberg, U. et al. Stomatal closure, basal leaf embolism and shedding protect the hydraulic integrity of grape stems. Plant Physiol. (2017)

37. Martin-StPaul, N., Delzon, S. \& Cochard, H. Plant resistance to drought depends on timely stomatal closure. Ecol. Lett. 20, 1437-1447 (2017). The absolute limit at which stomata must close to avoid mortality under drought is described

38. Li, X. et al. Tree hydraulic traits are coordinated and strongly linked to climateof-origin across a rainfall gradient. Plant Cell Environ. 41, 646-660 (2018).

39. Leigh, A., Sevanto, S., Close, J. D. \& Nicotra, A. B. The influence of leaf size and shape on leaf thermal dynamics: does theory hold up under natural conditions? Plant Cell Environ. 40, 237-248 (2017).

40. Powles, S. B. Photoinhibition of photosynthesis induced by visible light. Annu. Rev. Plant Physiol. 35, 15-44 (1984).

41. Mitchell, $P$. J. et al. Drought response strategies define the relative contributions of hydraulic dysfunction and carbohydrate depletion during tree mortality. New Phytol. 197, 862-872 (2013).

42. Sevanto, S., McDowell, N. G., Dickman, L. T., Pangle, R. \& Pockman, W. T. How do trees die? A test of the hydraulic failure and carbon starvation hypotheses. Plant Cell Environ. 37, 153-161 (2014).

43. Dietze, M. C. \& Matthes, J. H. A general ecophysiological framework for modelling the impact of pests and pathogens on forest ecosystems. Ecol. Lett. 17, 1418-1426 (2014)

44. Kerstiens, G. Cuticular water permeability and its physiological significance. J. Exp. Bot. 47, 1813-1832 (1996).

45. Oren, R. \& Pataki, D. E. Transpiration in response to variation in microclimate and soil moisture in southeastern deciduous forests. Oecologia 127, 549-559 (2001).

46. Zhang, Y.-J., Rockwell, F. E., Graham, A. C., Alexander, T. \& Holbrook, N. M. Reversible leaf xylem collapse: a potential "circuit breaker" against cavitation. Plant Physiol. 172, 2261-2274 (2016).

47. McElrone, A. J. et al. Aquaporin-mediated changes in hydraulic conductivity of deep tree roots accessed via caves. Plant Cell Environ. 30, 1411-1421 (2007)

48. Sack, L. \& Holbrook, N. M. Leaf hydraulics. Annu. Rev. Plant Biol. 57, 361-381 (2006)

49. Cuneo, I. F., Knipfer, T., Brodersen, C. R. \& McElrone, A. J. Mechanical failure of fine root cortical cells initiates plant hydraulic decline during drought. Plant Physiol. 172, 1669-1678 (2016).

50. Borchert, R. \& Pockman, W. T. Water storage capacitance and xylem tension in isolated branches of temperate and tropical trees. Tree Physiol. 25, 457-466 (2005).

51. Choat, B., Brodersen, C. R. \& McElrone, A. J. Synchrotron X-ray microtomography of xylem embolism in Sequoia sempervirens saplings during cycles of drought and recovery. New Phytol. 205, 1095-1105 (2015).

52. Brodribb, T. J. et al. Visual quantification of embolism reveals leaf vulnerability to hydraulic failure. New Phytol. 209, 1403-1409 (2016).

53. Tyree, M. T., Cochard, H., Cruiziat, P., Sinclair, B. \& Ameglio, T. Drought-induced leaf shedding in walnut: evidence for vulnerability segmentation. Plant Cell Environ. 16, 879-882 (1993)

54. Rood, S. B., Patiño, S., Coombs, K. \& Tyree, M. T. Branch sacrifice: cavitationassociated drought adaptation of riparian cottonwoods. Trees 14, 248-257 (2000)

55. Choat, B. et al. Noninvasive measurement of vulnerability to droughtinduced embolism by X-ray microtomography. Plant Physiol. 170, 273-282 (2016).

56. Larter, M. et al. Aridity drove the evolution of extreme embolism resistance and the radiation of conifer genus Callitris. New Phytol. 215, 97-112 (2017).

57. Pittermann, J. The evolution of water transport in plants: an integrated approach. Geobiology 8, 112-139 (2010).

58. Blackman, C. J. et al. Toward an index of desiccation time to tree mortality under drought. Plant Cell Environ. 39, 2342-2345 (2016).

A process-based approach is used to model desiccation time to mortality in trees under drought

59. Bartlett, M. K., Klein, T., Jansen, S., Choat, B. \& Sack, L. The correlations and sequence of plant stomatal, hydraulic, and wilting responses to drought. Proc Natl Acad. Sci. USA 113, 13098-13103 (2016).

60. Choat, B. et al. Global convergence in the vulnerability of forests to drought. Nature 491, 752-755 (2012).

Global synthesis demonstrating a convergence in tree hydraulic safety margins across forest biomes.
61. Maherali, H., Pockman, W. T. \& Jackson, R. B. Adaptive variation in the vulnerability of woody plants to xylem cavitation. Ecology 85, 2184-2199 (2004).

62. Lens, F. et al. Testing hypotheses that link wood anatomy to cavitation resistance and hydraulic conductivity in the genus Acer. New Phytol. 190, 709-723 (2011).

63. Pittermann, J. et al. The relationships between xylem safety and hydraulic efficiency in the Cupressaceae: the evolution of pit membrane form and function. Plant Physiol. 153, 1919-1931 (2010).

64. Blackman, C. J., Brodribb, T. J. \& Jordan, G. J. Leaf hydraulic vulnerability influences species' bioclimatic limits in a diverse group of woody angiosperms. Oecologia 168, 1-10 (2012).

65. Mencuccini, M., Minunno, F., Salmon, Y., Martínez-Vilalta, J. \& Hölttä, T. Coordination of physiological traits involved in drought-induced mortality of woody plants. New Phytol. 208, 396-409 (2015).

66. Reich, P. B. The world-wide 'fast-slow' plant economics spectrum: a traits manifesto. J. Ecol. 102, 275-301 (2014).

67. Anderegg, W. R. et al. Meta-analysis reveals that hydraulic traits explain cross-species patterns of drought-induced tree mortality across the globe. Proc. Natl Acad. Sci. USA 113, 5024-5029 (2016).

68. Rowland, L. et al. Death from drought in tropical forests is triggered by hydraulics not carbon starvation. Nature 528, 119-122 (2015).

69. Lamy, J.-B. et al. Limited genetic variability and phenotypic plasticity detected for cavitation resistance in a Mediterranean pine. New Phytol. 201, 874-886 (2014).

70. Schuldt, B. et al. How adaptable is the hydraulic system of European beech in the face of climate change-related precipitation reduction? New Phytol. 210, 443-458 (2016)

71. Mencuccini, M. \& Grace, J. Climate influences the leaf area/sapwood area ratio in Scots pine. Tree Physiol. 15, 1-10 (1995).

72. Magnani, F., Mencuccini, M. \& Grace, J. Age-related decline in stand productivity: the role of structural acclimation under hydraulic constraints. Plant Cell Environ. 23, 251-263 (2000)

73. Maherali, H. \& DeLucia, E. H. Xylem conductivity and vulnerability to cavitation of ponderosa pine growing in contrasting climates. Tree Physiol. 20, 859-867 (2000).

74. Martínez-Vilalta, J. et al. Hydraulic adjustment of Scots pine across Europe. New Phytol. 184, 353-364 (2009).

Comprehensive study of intra-specific variation in hydraulic traits across a broad climatic gradient.

75. Wortemann, R. et al. Genotypic variability and phenotypic plasticity of cavitation resistance in Fagus sylvatica L. across Europe. Tree Physiol. 31 , 1175-1182 (2011).

76. Hogg, E. H., Brandt, J. P. \& Kochtubajda, B. Growth and dieback of aspen forests in northwestern Alberta, Canada, in relation to climate and insects. Can. J. For. Res. 32, 823-832 (2002).

77. Sperry, J. S. \& Love, D. M. What plant hydraulics can tell us about responses to climate-change droughts. New Phytol. 207, 14-27 (2015).

78. Delzon, S. \& Cochard, H. Recent advances in tree hydraulics highlight the ecological significance of the hydraulic safety margin. New Phytol. 203, 355-358 (2014)

79. Anderegg, W. R. L. et al. Tree mortality predicted from drought-induced vascular damage. Nat. Geosci. 8, 367-371 (2015).

80. McDowell, N. G. et al. Multi-scale predictions of massive conifer mortality due to chronic temperature rise. Nat. Clim. Change 6, 295-300 (2016).

81. Brodribb, T. J., Bowman, D. J. M. S., Nichols, S., Delzon, S. \& Burlett, R. Xylem function and growth rate interact to determine recovery rates after exposure to extreme water deficit. New Phytol. 188, 533-542 (2010).

82. Meinzer, F. C., Johnson, D. M., Lachenbruch, B., McCulloh, K. A. \& Woodruff, D. R. Xylem hydraulic safety margins in woody plants: coordination of stomatal control of xylem tension with hydraulic capacitance. Funct. Ecol. 23, 922-930 (2009).

83. McDowell, N. G. et al. Evaluating theories of drought-induced vegetation mortality using a multimodel-experiment framework. New Phytol. 200, 304-321 (2013).

84. Gustafson, E. J. \& Sturtevant, B. R. Modeling forest mortality caused by drought stress: implications for climate change. Ecosystems 16, 60-74 (2013).

85. Mitchell, P. J. et al. An ecoclimatic framework for evaluating the resilience of vegetation to water deficit. Glob. Chang. Biol. 22, 1677-1689 (2016).

86. O'Sullivan, O. S. et al. Thermal limits of leaf metabolism across biomes. Glob. Chang. Biol. 23, 209-223 (2017).

87. Adams, H. D. et al. Empirical and process-based approaches to climateinduced forest mortality models. Front. Plant Sci. 4, 438 (2013).

88. Christoffersen, B. O. et al. Linking hydraulic traits to tropical forest function in a size-structured and trait-driven model (TFS v.1-Hydro). Geosci. Model Dev. 9 4227-4255 (2016).

89. Xu, X., Medvigy, D., Powers, J. S., Becknell, J. M. \& Guan, K. Diversity in plant hydraulic traits explains seasonal and inter-annual variations of vegetation dynamics in seasonally dry tropical forests. New Phytol. 212, 80-95 (2016).

90. Davi, H. \& Cailleret, M. Assessing drought-driven mortality trees with physiological process-based models. Agric. For. Meteorol. 232, 279-290 (2017).

91. Bartlett, M. K., Scoffoni, C. \& Sack, L. The determinants of leaf turgor loss point and prediction of drought tolerance of species and biomes: a global meta-analysis. Ecol. Lett. 15, 393-405 (2012).

Data synthesis that links the point at which leaf turgor is lost to drought tolerance in plants. 
92. Limousin, J.-M., Longepierre, D., Huc, R. \& Rambal, S. Change in hydraulic traits of Mediterranean Quercus ilex subjected to long-term throughfall exclusion. Tree Physiol. 30, 1026-1036 (2010).

93. Vilagrosa, A., Bellot, J., Vallejo, V. R. \& Gil-Pelegrín, E. Cavitation, stomata conductance, and leaf dieback in seedlings of two co-occurring Mediterranean shrubs during an intense drought. J. Exp. Bot. 54, 2015-2024 (2003).

94. Dahlin, K. M., Ponte, D. D., Setlock, E. \& Nagelkirk, R. Global patterns of drought deciduous phenology in semi-arid and savanna-type ecosystems. Ecography 40, 314-323 (2016)

95. De Kauwe, M. G. et al. Do land surface models need to include differential plant species responses to drought? Examining model predictions across a mesic-xeric gradient in Europe. Biogeosciences 12, 7503-7518 (2015).

96. Aguadé, D., Poyatos, R., Rosas, T. \& Martínez-Vilalta, J. Comparative drought responses of Quercus ilex L. and Pinus sylvestris L. in a montane forest undergoing a vegetation shift. Forests 6, 2505 (2015).

97. Donovan, L., Linton, M. \& Richards, J. Predawn plant water potential does not necessarily equilibrate with soil water potential under well-watered conditions. Oecologia 129, 328-335 (2001).

98. Nobel, P. S. \& Cui, M. Hydraulic conductances of the soil, the root-soil air gap, and the root: changes for desert succulents in drying soil. J. Exp. Bot. 43, 319-326 (1992)

99. Eller, C. B., Lima, A. L. \& Oliveira, R. S. Cloud forest trees with higher foliar water uptake capacity and anisohydric behavior are more vulnerable to drought and climate change. New Phytol. 211, 489-501 (2016).

100. Sinclair, T. R. Model analysis of plant traits leading to prolonged crop survival during severe drought. Field Crops Res. 68, 211-217 (2000).

101. Manzoni, S., Katul, G. \& Porporato, A. A dynamical system perspective on plant hydraulic failure. Wat. Resour. Res. 50, 5170-5183 (2014).

102. Gentine, P., Guérin, M., Uriarte, M., McDowell, N. G. \& Pockman, W. T. An allometry-based model of the survival strategies of hydraulic failure and carbon starvation. Ecohydrology 9, 529-546 (2016).

103. Waring, R. H. Characteristics of trees predisposed to die. Bioscience 37, 569-574 (1987).

104. Bréda, N., Huc, R., Granier, A. \& Dreyer, E. Temperate forest trees and stands under severe drought: a review of ecophysiological responses, adaptation processes and long-term consequences. Ann. For. Sci. 63, 625-644 (2006).

105. De Micco, V., Balzano, A., Wheeler, E. A. \& Baas, P. Tyloses and gums: a review of structure, function and occurrence of vessel occlusions. IAWA J. 37, 186-205 (2016)

106. Zeppel, M. J. B. et al. Drought and resprouting plants. New Phytol. 206, 583-589 (2015)

107. Bond, W. J. \& Midgley, J. J. Ecology of sprouting in woody plants: the persistence niche. Trends Ecol. Evol. 16, 45-51 (2001)

108. Brodersen, C. R. \& McElrone, A. J. Maintenance of xylem network transport capacity: a review of embolism repair in vascular plants. Front. Plant Sci. 4, 108 (2013)

109. Zwieniecki, M. A. \& Holbrook, N. M. Confronting Maxwell's demon: biophysics of xylem embolism repair. Trends Plant Sci. 14, 530-534 (2009).

110. Nardini, A., Savi, T., Trifilò, P. \& Lo Gullo, M. A. in Progress in Botany Vol. 79 (eds Cánovas, F. et al.) 197-231 (Springer, Cham, 2017).

111. Cobb, A. R., Choat, B. \& Holbrook, N. M. Dynamics of freeze-thaw embolism in Smilax rotundifolia (Smilacaceae). Am. J. Bot. 94, 640-649 (2007)

112. Cochard, H., Lemoine, D., Améglio, T. \& Granier, A. Mechanisms of xylem recovery from winter embolism in Fagus sylvatica. Tree Physiol. 21, 27-33 (2001).

113. Sperry, J. S., Holbrook, N. M., Zimmermann, M. H. \& Tyree, M. T. Spring filling of xylem vessels in wild grapevine. Plant Physiol. 83, 414-417 (1987)

114. Kaufmann, I. et al. Functional repair of embolized vessels in maize roots after temporal drought stress, as demonstrated by magnetic resonance imaging. New Phytol. 184, 245-256 (2009).

115. McCully, M. E., Huang, C. X. \& Ling, L. E. C. Daily embolism and refilling of xylem vessels in the roots of field-grown maize. New Phytol. 138, 327-342 (1998).

116. Taneda, H. \& Sperry, J. S. A case-study of water transport in co-occurring ring-versus diffuse-porous trees: contrasts in water-status, conducting capacity, cavitation and vessel refilling. Tree Physiol. 28, 1641-1651 (2008).

117. Zwieniecki, M. A. \& Holbrook, N. M. Diurnal variation in xylem hydraulic conductivity in white ash (Fraxinus americana L.), red maple (Acer rubrum L.) and red spruce (Picea rubens Sarg.). Plant Cell Environ. 21, 1173-1180 (1998).
118. Brodersen, C. R., McElrone, A. J., Choat, B., Matthews, M. A. \& Shackel, K. A. The dynamics of embolism repair in xylem: in vivo visualizations using highresolution computed tomography. Plant Physiol. 154, 1088-1095 (2010).

First study to utilize synchrotron-based imaging methods for non-destructive visualization of xylem function.

119. Charrier, G. et al. Evidence for hydraulic vulnerability segmentation and lack of xylem refilling under tension. Plant Physiol. 172, 1657-1668 (2016).

120. Clearwater, M. J. \& Clark, C. J. In vivo magnetic resonance imaging of xylem vessel contents in woody lianas. Plant Cell Environ. 26, 1205-1214 (2003).

121. Knipfer, T., Brodersen, C. R., Zedan, A., Kluepfel, D. A. \& McElrone, A. J. Patterns of drought-induced embolism formation and spread in living walnut saplings visualized using X-ray microtomography. Tree Physiol. 35, 744-755 (2015).

122. Skelton, R. P., Brodribb, T. J., McAdam, S. A. M. \& Mitchell, P. J. Gas exchange recovery following natural drought is rapid unless limited by loss of leaf hydraulic conductance: evidence from an evergreen woodland. New Phytol. 215, 1399-1412 (2017).

123. Fukuda, H. Xylogenesis: initiation, progression, and cell death. Annu. Rev. Plant Physiol. Plant Mol. Biol. 47, 299-325 (1996).

124. Davies, W., Metcalfe, J., Lodge, T. \& da Costa, A. R. Plant growth substances and the regulation of growth under drought. Funct. Plant Biol. 13, 105-125 (1986).

125. Liang, E., Balducci, L., Ren, P. \& Rossi, S. in Secondary Xylem Biology: Origins, Functions, and Applications (eds Kim, Y.S. et al.) 45-58 (Academic, Cambridge, 2016).

126. Hartmann, H. Will a 385 million year-struggle for light become a struggle for water and for carbon? - How trees may cope with more frequent climate change-type drought events. Glob. Chang. Biol. 17, 642-655 (2011)

127. Brunner, I., Herzog, C., Dawes, M. A., Arend, M. \& Sperisen, C. How tree roots respond to drought. Front. Plant Sci. 6, 547 (2015).

128. Kozlowski, T. \& Pallardy, S. Acclimation and adaptive responses of woody plants to environmental stresses. Bot. Rev. 68, 270-334 (2002)

129. Pagay, V. et al. A microtensiometer capable of measuring water potentials below -10 MPa. Lab Chip 14, 2806-2817 (2014).

130. Luo, Z. et al. Responses of plant water use to a severe summer drought for two subtropical tree species in the central southern China. J. Hydrol. 8, 1-9 (2016).

131. Cochard, H. et al. Methods for measuring plant vulnerability to cavitation: a critical review. J. Exp. Bot. 64, 4779-4791 (2013)

132. Poyatos, R. et al. SAPFLUXNET: towards a global database of sap flow measurements. Tree Physiol. 36, 1449-1455 (2016).

133. McDowell, N. G. et al. Global satellite monitoring of climate-induced vegetation disturbances. Trends Plant Sci. 20, 114-123 (2015).

Acknowledgements We thank S. Stuart, H. Cochard and M. Holbrook for insightful comments and discussion during the preparation of the Review. Micro-computed tomography images included in Fig. 2 were collected during beam-time allocations at the Imaging and Medical beam line (Australian Synchrotron) and TOMCAT beam line (Swiss Light Source). B.C., T.J.B. and B.E.M. acknowledge support from the Australian Research Council (FT130101115; LP140100232; DP170100761). R.L. was supported by a Marie Curie Fellowship (FP7PEOPLE-2013-IOF-624473).

Reviewer information Nature thanks B. Engelbrecht, N. G. McDowell and M. Mencuccini for their contribution to the peer review of this work.

Author contributions All authors contributed to writing and planning of the manuscript. B.C., T.J.B. and B.E.M. developed the initial outline and synopsis of the Review. B.C. was responsible for the coordination of the writing of the manuscript. B.C. and C.R.B. prepared figures and the table.

Competing interests The authors declare no competing interests.

Additional information

Supplementary information is available for this paper at https://doi.org/ 10.1038/s41586-018-0240-x.

Reprints and permissions information is available at http://www.nature.com/ reprints.

Correspondence and requests for materials should be addressed to B.C.

Publisher's note: Springer Nature remains neutral with regard to jurisdictional claims in published maps and institutional affiliations. 